\title{
COORDINATORS BRIDGE RESIDENTS AND ARTISTS IN REGIONAL JAPAN: A CASE STUDY OF THE ART PROJECT HANARART
}

\author{
Shiro Horiuchi* \\ Faculty of International Tourism, Hannan University, \\ 1-108-1 Amamiminami Matsubara, Osaka, Japan 580-0033 \\ email: horiuchi.shiro@gmail.com
}

Published online: 15 July 2017

To cite this article: Horiuchi, S. 2017. Coordinators bridge residents and artists in regional Japan: A case study of the art project Hanarart. International Journal of Asia Pacific Studies 13 (2): 1-22, https://doi.org/10.21315/ijaps2017.13.2.1

To link to this article: https://doi.org/10.21315/ijaps2017.13.2.1

\begin{abstract}
In the age of globalisation, the transiency of individuals has been increasing. Consequently, some regional communities face the risk of collapse and disappearance. Particularly in Japan, centralisation in and around global cities such as Tokyo has accelerated the decline of regional communities. Given this current clime, residents of regional areas would benefit from building ties with outsiders in order to keep their communities strong. Certain individuals could take on the role of coordinator, who can work to bridge the gap between the residents and outsiders. The role of the coordinator, however, is not yet clear. This study introduces a case study of the art project Hanarart (はならあと) which involves residents and outside artists in regional areas of Nara, Japan. Part of the art project intends to renovate and reuse the machiya buildings in Japanese traditional style, with the help of site-specific contemporary art that will fit well with the machiya style. In the art project, outside artists prepare their artworks in the abandoned buildings, which are managed by the residents. During the first stage of the project, residents and artists did not communicate well due to either their indifference or ignorance toward each other's interests. In the next stage, however, assigned coordinators promoted communication between the residents and artists for the sake of contemporary art. Through the process of trial and error, the project resulted in contributing to the community in a number of ways. The renovated and repurposed machiya buildings helped to develop communication among the various individuals, which led to the building of
\end{abstract}


culturally creative areas. These areas have proved inspiring for regional community members with the involvement of various outsiders in community activities.

Keywords: Coordinator, community development, cultural creative area, contemporary art, renovation and repurpose

\section{INTRODUCTION}

In the age of globalisation, the influx of materials has increased extensively, such as information, products and people, across the boundary of all regions in the global range. The influx of individuals has affected regional communities, which may lead to collapse and disappearance (Delanty 2003). Industrial changes accompanied with globalisation are also likely to damage regional communities (Sassen 2001). This study aims to clarify how regional communities address the problems accompanying globalisation through a case study of a Japanese regional area.

Classically, regional communities are a collection of homogenous local residents (MacIver 1924; Dore 1994). Residents were acquainted with each other as relatives or neighbours in a small area. Residents gain various benefits from their communities, such as cooperative labour, improvements in health and a sense of well-being, management of common property resources, and trust and assurance among themselves (Coleman 1988; Woolcock 1998). They grew up with shared symbols that distinguish residents from outsiders, or made a distinction between "us and them" (Calhoun 1980; Cohen 1985). Residents and outsiders could not be expected to work collaboratively in the construction of their shared symbols. Accordingly, residents in some regions may attempt to keep outsiders out, in order to retain their benefits, defending themselves against free riders. Owing to dense and closed networks among the residents, they could monitor and give sanctions to free riders, or outsiders, who violated the norms of their community (Olson 1965; Hechter 1987; Ostrom 1990).

We now introduce regional communities of Japan. Rural areas were historically composed of hamlets, or shizen-son, which had fixed numbers of membership. Residents lived most of their lives in these hamlets, where they were assumed to share the same ancestors. They excluded outsiders from their shared resources (Suzuki 1968). In urban areas, on the other hand, neighborhood associations, or jichikai, often represented the functions of communities. Residents were expected to cooperate with each other in order to improve the infrastructure of the area, with an underlying concept of participatory democracy. The transiency of individuals was high in urban 
areas. Therefore, newcomers were expected to participate in community activities, implicitly assuming the boundary against any outsiders who were indifferent to their community activities (Okuda 1983). Occasionally, regional communities welcomed some types of outsiders as visitors or new members; outsiders were still discriminated against in many respects by local residents and were often excluded from the communities (Orikuchi 2003).

Now, regional communities face an increasing number of outsiders and, as such, it is difficult for the residents to monitor all outsiders. Residents may retain the benefits by making the boundary of their community fixed and closed, excluding outsiders. However, other downsides are likely to appear, such as loss of information, lack of entrepreneurship, and xenophobia toward outsiders (Portes 1998). Those with a dislike for these types of disadvantages in their areas may feel the need to leave, in which case the number of residents, particularly those with talent and ability, might decrease.

In Japan, globalisation has accelerated industrial changes, particularly since the recession of 1993. Information and finance industries have expanded, accumulating in and around a few large cities, particularly Tokyo. The manufacturing industry, which used to employ many workers in regional areas, has taken factories abroad in order to access cheaper labour (Sassen 2001). Opportunities in higher education are also concentrated around the larger mega-cities (Horiuchi and Takahashi 2016). Individuals, particularly those demonstrating talent, seek out job and education opportunities which are much more readily available in the cities. On the other hand, Tokyo, the largest global city in East Asia, shows the lowest total fertility rate among all prefectures in Japan. Many young individuals face tough, over-urbanised environments for raising children in or around Tokyo, such as few nurseries, no help from relatives, and long hours spent working and commuting. The difficult social situation in Tokyo traps many individuals from regional areas. Masuda (2014) describes Tokyo as a "black hole of depopulation." Now, regional revitalisation has become the most important political issue in Japan. Regional communities are expected to attract and retain immigrants/residents not only for their own survival but also for the society and economy of all Japan.

Taking account of these conditions, residents of modern regional communities should take steps to involve more outsiders in their community activities. The relationship between residents and outsiders should be more of a loose connection (Wuthnow 1998), as compared to the more fixed and dense connections among residents of traditional regional communities. Loose connections may not only help to recover the original benefits of living in a 
traditional community but may also bring new benefits, which become possible once solid communication is established among heterogeneous individuals, including residents and outsiders. New benefits could include bringing new ideas, economic growth, innovation, and improved democracy. These benefits have also been discussed as gains in bridging social capital, in contrast to bonding social capital that corresponds to traditional local communities of homogenous membership (Putnam 2000). If we could establish a number of loose connections in traditional communities, or generate the bonding and bridging of social capital, we might see real benefits. In fact, regions with a higher tolerance for diversity are, in all likelihood, already welcoming many creative talents, which contribute to the building of culturally creative areas involving various benefits (Jacobs 1984; Landry 2000; Florida 2002). If we could promote culturally creative areas in regional communities, we might counter the negative effects of globalisation. Individuals, particularly the young and talented, might remain in or migrate to regional areas that show support for cultural creativity.

\section{AN ART PROJECT IN REGIONAL JAPAN}

This study introduces an art project in a regional area of Japan as a case study for building loose connections between residents and outsiders. A number of art projects are underway in various areas of Japan. The Naoshima project (2002-), led by Setouchi Triennale (2010-), is a well-known regional art project in Japan. More than one million people visited the site area during the project period in 2013, and more may visit in 2016. The Echigo-Tsumari Art Triennial (2000-) is another well-known project, which has had the involvement of more than 500,000 audience members during the project period in 2015. Furamu Kitagawa, the general director of these two largest art projects, stated that the two art projects intend regional revitalisation (Fujita 2016).

Following on from the success of these well-known art projects, the number of other art projects in Japan has been increasing (Figure 1). However, not all art projects involve as many materials as Setouchi Triennale and EchigoTsumari Art Triennial. Small art projects, now abundant in many regional areas, are finding other ways to pursue their identities and survive.

Art projects are often implemented as relational art (Bourriaud 2002). Residents and outsiders are expected to communicate about the art projects. In the art project, the artist is considered the operator of meaning, coordinating a number of subjects. The romantic notion of the artist as genius is discounted. In fact, relational art takes its theoretical horizon from the realm 
of human interaction and its social context, rather than the assertion of an independent and private symbolic space. Art projects also include the idea of site specificity (Kwon 2004), which questions present lifestyles in the site area by involving residents as audience and also as artists. Through experiencing art products, artists, audience, residents and outsiders collaboratively find the shared meaning of the site. In the site area, collective work between artists and audiences expands their collective identity and sense of community (Newman et al. 2003; Stuiver et al. 2013).

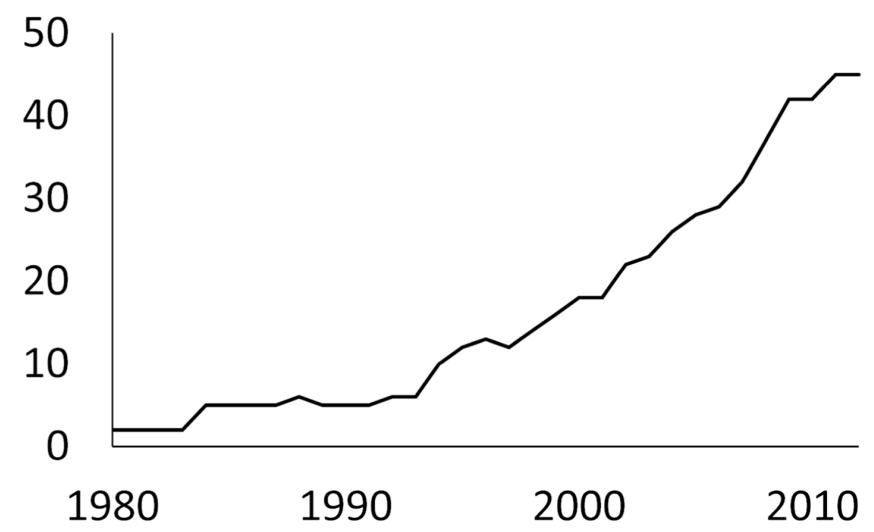

Figure 1: The number of art projects held in Japan (after Kumakura 2014).

Artists and audience, or residents and outsiders, are required to communicate to reconstruct their shared communities, particularly in small art projects. In such art projects, residents should include some artists and comprise a large section of the audience. Outsiders should include many artists and comprise some of the audience visiting the region during an art project. The audience and the artists should appropriately correspond to residents and outsiders. Hereafter this study uses the terms "residents" and "artists," corresponding to audience and outsiders, respectively.

In order to build connections between residents and outsiders, some individuals can adopt the role of coordinator. Having certain individuals take the lead in arranging collaborations between different regions or organisations would see connections starting to form. Without coordinators, residents are more likely to be indifferent, or even hostile, toward outsiders, especially where their network is particularly dense and closed. Outsiders would find it extremely challenging to communicate with residents without the aid of coordinators.

Coordinators may be regarded as having ties (Granovetter 1973), or situated within structural holes (Burt 1992), which can bridge the gap between residents and outsiders. Previous studies have shown how coordinators can access benefits owing to their social position within structural holes, as 
compared to other individuals who are not in such positions (Lin 2001). However, weak ties, which extend across the boundary of fixed membership within a community, may bring benefits not only to the coordinators, but also to the residents and outsiders (Horiuchi 2008; Horiuchi et al. 2013).

Few previous studies have discussed the role of coordinators in the building of loose connections between residents and outsiders in regional areas of Japan (Sasaki 2012; Sasaki et al. 2014). In art projects, the role of the coordinator is important, since the connection between residents and artists can often be difficult (Helguera 2011). The relevant question is, "Who takes on the role of coordinating in a small art project?"

\section{ART PROJECT HANARART}

Nara is a prefecture in the Western part of Japan. The oldest capital of Japan was located in the prefecture. Until the eighth century, Japanese emperors constructed palaces in Nara. Nara is well known as a Buddhist prefecture. It includes more than hundreds of national treasures relating to Buddhist culture. There are also three UNESCO cultural heritage sites in the prefecture, highest among all 47 prefectures in Japan. Furthermore, many tourists visit Nara for sight-seeing.

Despite its strong standpoint as the oldest capital and tourist area, regional communities in Nara are facing decline. Nara is adjacent to Osaka prefecture, which is the second-largest city in Japan. Many tourists visit Nara on one-day trips and stay in Osaka at night. Loading industries and restaurant businesses do not thrive in Nara. On the contrary, many Nara residents visit Osaka during the daytime as employees and consumers. The population ratio of daytime to nighttime in Nara is small. Few residents take part in community activities. The abandonment of traditional Japanese buildings, machiya, represents how the decline of the area has become a serious.

Machiya feature degoshi (wooden latticework windows) and mushikomado (lattice-like wall slits upstairs for letting in air and light). Usually facing the street, machiya have been used as both dwellings and workplaces. Towns with machiya form a beautiful landscape that attracts many tourists (Figure 2). Naramachi, a town famous for machiya in Nara prefecture, attracts many tourists. However, it is an exception. Many owners of machiya buildings are now old and not motivated to maintain the buildings. Their children do not want to inherit the buildings. Hence, few individuals manage machiya buildings. Many machiya buildings, and towns featuring machiya, have been abandoned. 


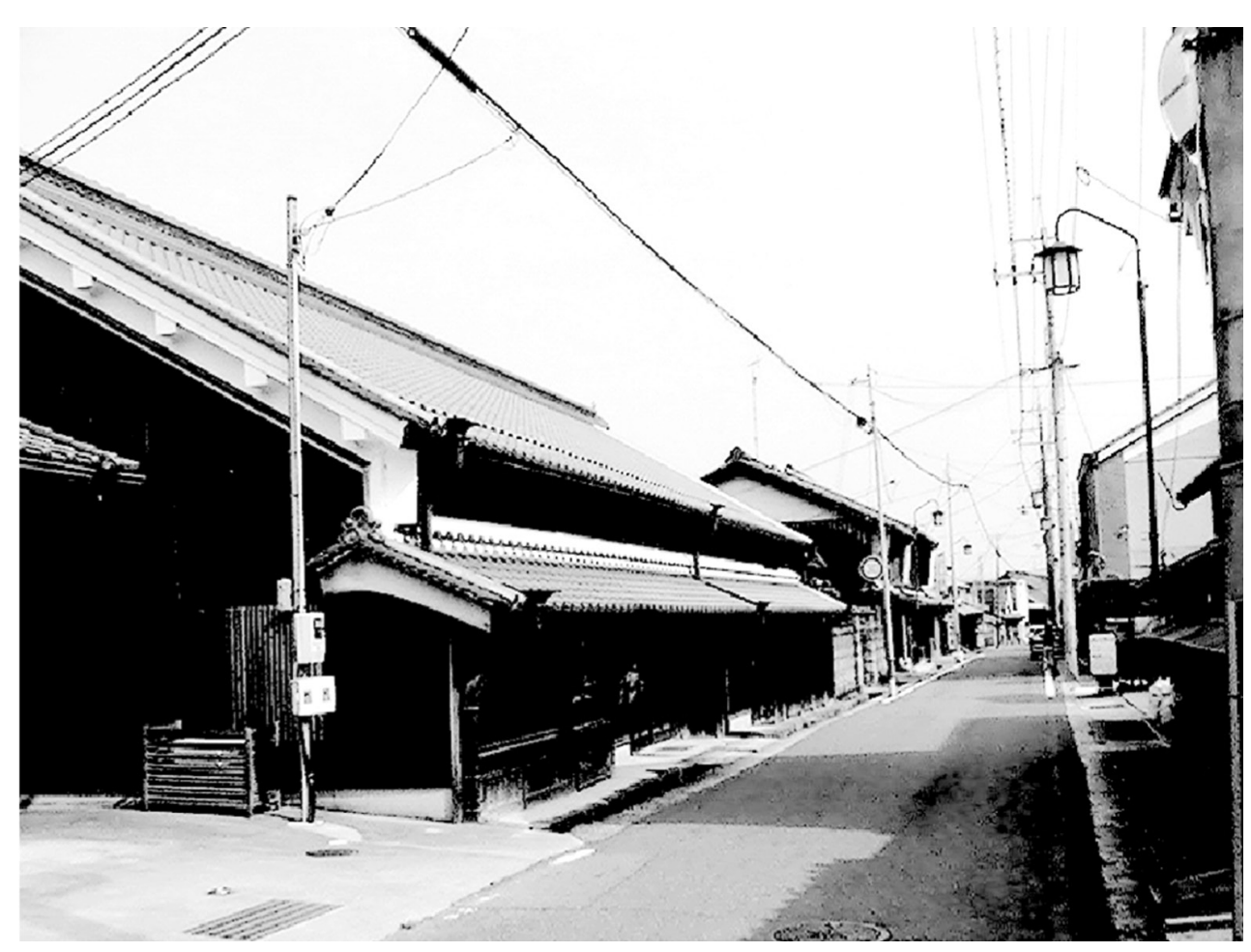

Figure 2: The portrait of machiya-style buildings.

The art project Hanarart (はならあと in Japanese literature) started in Nara prefecture in 2011. The name Hanarart is composed of "Hana," "Nara" and "Art." The first word, "Hana," means flower, which was the common symbol for the art project. The project was originally organised in 2010 by an individual who managed a gallery in Nara. He wished to expand the culture of contemporary art in Nara. At that time, the art project was not involved in town planning, but the organiser was able to use some abandoned machiya buildings as exhibition sites by chance. A civil servant saw the art project and thought that it could contribute to community development. Following her leadership, the Nara local government started the Hanarart project as a strategy for town planning since 2011. Hanarart was thus originally intended to promote the renovation and repurposing of machiya buildings that had been abandoned in many areas of Nara prefecture; the intention to expand the culture of contemporary art in Nara was secondary.

The Nara prefectural government took responsibility for organising the Hanarart office. The office employed a couple of full-time staff members for the project. It initially announced the art project to resident groups in Nara prefecture. Several resident groups from all around Nara prefecture voluntarily took part in the project. The Hanarart office and resident groups organise the Hanarart committee each year. Ten (2011), six (2012), eight (2013), eight (2014), and five (2015) resident groups have taken part in the project (see 
Figure 3). In total, 15 resident groups have been involved with the project throughout the year 2015. There are plans for the project to continue into 2016 and beyond.

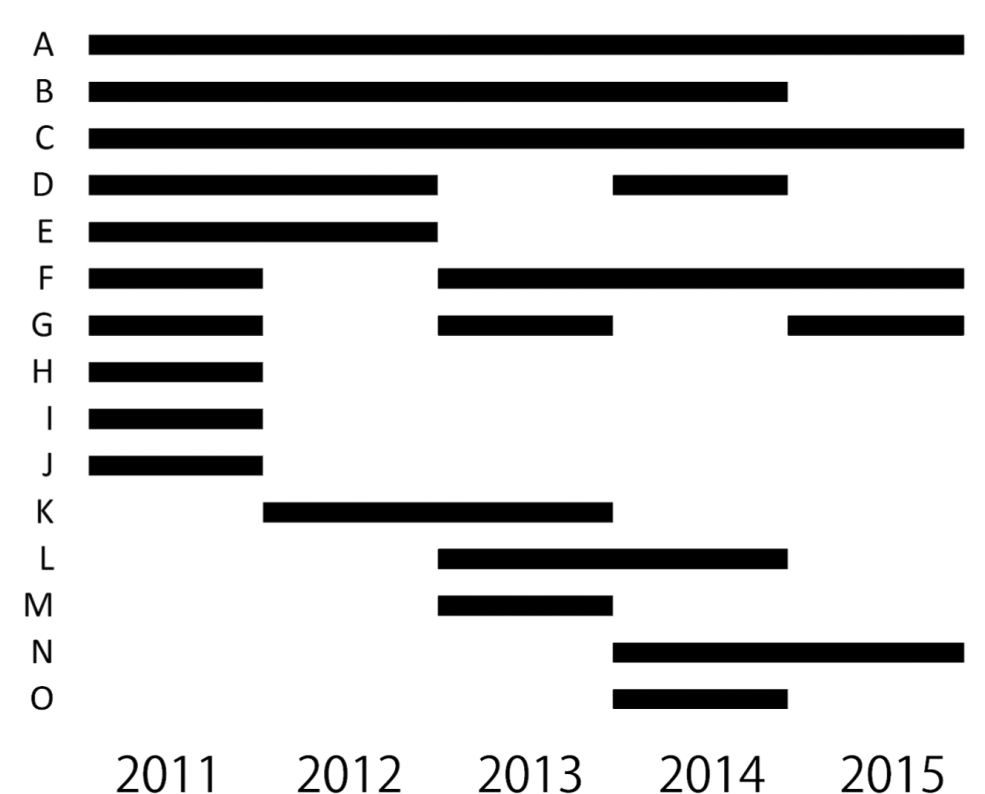

Figure 3: Residents groups that attended the Hanarart project each year.

Artists bring or create their artworks that aim to align with the content of the prepared machiya buildings. The project aims to ensure that the value of the machiya buildings is evident. It has also tried to allow the owners or other residents to determine the value of their machiya buildings through communication with outsiders. It was expected that some outsiders would discuss the buildings with the residents at the art project gatherings. Residents and outsiders could collaboratively renovate and repurpose the buildings, such as their houses or shops, for their own interests. The art project also collaborated with other local events led by residents.

\section{CONFLICTS BETWEEN ART AND COMMUNITY}

The author conducted a fieldwork study on the Hanarart project. He took part in the art project as a member of the audience. He interviewed the stakeholders and gathered data with respect to the art project as well as the communities during or before and after the art project. The method of fieldwork excels in elucidating the exact relationships between cause and effect. Researchers can gain information on the thoughts of stakeholders by intensive survey. 
However, this methodology cannot accumulate large amounts of data. It is difficult to use statistical analysis with only from the acquired data. Thus, later studies should test the present study by comparing with other case studies. Fieldwork studies should be accumulated to acquire objective results.

The author interviewed organising civil servants and staff of the Hanarart office. They informed him that the art project had changed its emphasis from community development to contemporary art in 2013. The change occurred because the residents have realised the value of contemporary art through the two years of art projects. The extent of art projects also expanded in 2013 compared to the previous two years.

The author took part in the art project and interviewed all the artists who attended the project from September to November 2013. Many artists told him they were satisfied with the project. The project gave them the opportunity to present their artwork, as well as the opportunity to communicate with other artists and audience members. Many artists said that without this opportunity they could not have communicated with the various individuals as they did. Some artists, who live in Nara and adjacent areas, discovered the value of machiya for the first time on attending the project. Some artists came from abroad and stayed in the area for a few weeks. They talked with residents and acknowledged the hospitality that was extended to them during their stay. They also pointed the value of small art projects, since they represent the change of lifestyle in Japan from quantity to quality. One artist informed the author of his growth through communication with residents.

However, some artists criticised Hanarart in the sense that the art project was not distinguished from other art projects that were being held in Japan. It was suggested that many art projects, including Hanarart, were held as an easy way of ensuring community development, without any genuine discussion on the aspects of contemporary art. Artists were dissatisfied with the residents, in the sense that the residents did not understand the significance of contemporary art. One artist said:

Contemporary art originally tries to find problems and completely change the sense of values of the present. We are willing to communicate with residents to question their common sense. We are not afraid of troubles with them. However, many residents don't have a strong interest in discussing their area with us.

Another artist criticised residents for not trying to understand the aspects of contemporary art: 
Residents regard art projects as equivalent to their local festival. However, contemporary art can completely change the value of their locality as it involves many outsiders, such as us artists. However, residents do not communicate with us in sincerity.

One artist criticised the Hanarart project, saying:

The possibility of contemporary art lies in narratives where artists and residents collaboratively find value in art and the site. However, Hanarart, and other art projects as well, is not very conscious of this possibility. Art projects, except for large ones, cannot activate venue areas. They can only light a small fire to find the story of an area through narratives between artists and residents.

After the 2013 project, the author interviewed the leaders of the resident groups that had attended the Hanarart project. They had strong motivations for attracting the attention of other residents; there was very real concern about the situation of regional depopulation. They tried to show the value of machiya to other residents through the eyes of outsiders. For example, the Nara local government had ordered that an abandoned post office be renovated. However, none of the residents were able to present any kind of vision as to how the renovated post office could be used. One individual took charge of the renovation project, and later Hanarart. He was afraid of the residents' indifference toward their town. He said:

Many residents do not have visions of community development. I made use of Hanarart to highlight the buildings and inspire the residents. Particularly, I want to show the children that previous residents had put forth great efforts to activate the area. Children then later would take pride in their areas.

At the same time, the leaders of resident groups were afraid of the power of contemporary art, believing it might disturb the usual lives of the residents. They tried to counteract the effects of contemporary art so as not to disturb their town. For instance, one leader was dissatisfied with Hanarart, given its focus on contemporary art, saying:

Why does Hanarart have to be an art project of contemporary art? Many residents do not understand the value of contemporary art. I would rather put effort into preparing our own project in which local residents present their own artworks, which is more likely to involve a majority of the residents. 
Another leader noted the value of contemporary art, not because she loves contemporary art, but because contemporary art actually fits well with the image of machiya buildings. She said:

Nara is distinguished by its long history. The history can include our present lives as continuous from the past. Machiya buildings can easily include contemporary art, I believe, unless the art is not too grotesque.

Accordingly, many leaders took part in the project, not because they loved contemporary art, but because they wanted to involve residents in the machiya renovation and community development projects. They did not wish to upset the residents with contemporary art. At this point, artists and resident groups were not communicating well on reaching agreement about the future of the relationship between community development and art projects. The Hanarart committee were not able to prompt communication between residents and artists; rather, they tried to expand the extent of the project. Resident groups could not manage the areas in full and required the help of more residents in the project. Resident groups became tired and depressed about their work, and coordinating other residents and artists.

\section{COORDINATORS}

The fourth year of the project, 2014, was the turning point for Hanarart. An independent curator was assigned the role of general director for Hanarart 2014. He took part in Hanarart 2012 and was awarded "Most Valuable Player" that year. After the 2012 project, he started a contemporary art gallery in Osaka city. As such, he was well suited to the role of general director, as he not only knew the present Hanarart but could also envision its future. The role of general director is to determine the vision and direction of the art project and coordinate the relationship between residents and artists. During interview, he said:

Hanarart has been the worst of all the art projects in Japan. The reason being, in spite of very little funding, Hanarart has tried to involve too many artists and residents. Hanarart should not have involved artists and residents into its communications. Artists were not able to collaborate with residents to create site-specific art. Now I have put forward opportunities for genuine, open discussion between residents and artists, to make the power of each side equal. 
He made two important changes to the project in order to promote better communication between residents and artists. First, he gave more responsibility to a few curators and to the leaders of resident groups. Originally, the role of curators was to arrange artists and their art products in an exhibition. The role of curators becomes far more important in contemporary art projects. Without curators, the audience as well as artists can scarcely interpret and enjoy the meaning and significance of an exhibition. The general director also arranged opportunities for discussions between the curators and resident groups prior to the start of the project. In these discussions, the resident groups introduced the history and culture of their town to the curators. The curators then presented their ideas of how the resident groups and artists could collaborate on the project. Curators talked with the resident groups frequently until they had organised their venue. In addition, prior to and during the projects, the curators held several workshops that involved residents, artists and other outsiders. They discussed the possibility of art projects not only for community development, but also for the development of contemporary art, noting a possible contradiction between contemporary art and community. It is worth noting that Hanarart is now distinguishable from other art projects, with respect to its focus on the relationship between curators and residents groups.

The second change for Hanarart 2014 was the venue. The venues were categorised as either "Core" or "Plus." Curators organised machiya only into Core areas. They pursued the intended artworks themselves, by negotiating with residents groups. Resident groups organised the Plus areas by themselves. By preparing the Plus areas, residents were able to incorporate the history and culture of their area. From among the Plus areas of that year, the Core areas of the next year would be selected. Curators would organise the machiya buildings and determine which areas would be fitted with contemporary art. Therefore, resident groups had to consider the role and possibility of contemporary art for their area in a sincere manner prior to welcoming outsider curators, artists and audiences. Curators, on the other hand, could concentrate on the Core areas for the arranged artists and artworks, distinguishing themselves from the Plus areas. Figure 4 illustrates the relation between Core and Plus.

Under the guidance of the general director and through discussions between the curators and resident groups, the Hanarart committee tried to prioritise the quality of the art projects over quantity. It is important to note that the number of artists and audience members had changed. Figure 5 shows the extent to which Hanarart expanded from 2011 to 2013 and then shrank in 2014 and 2015. 


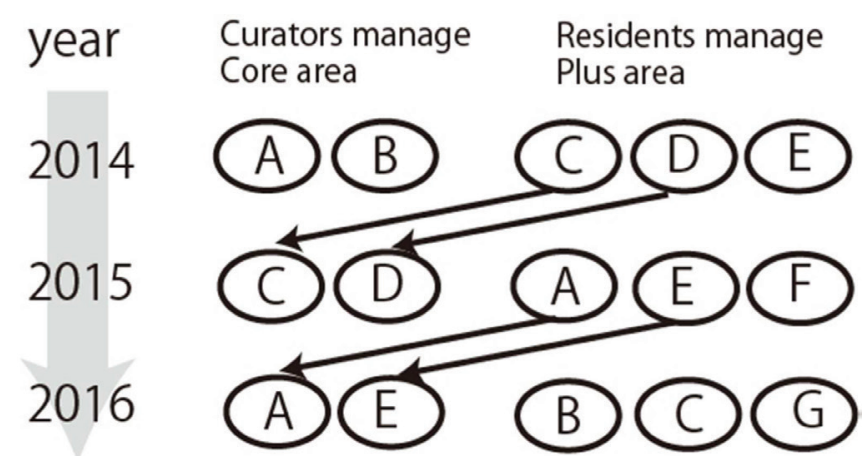

Figure 4: The relation between Core and Plus.

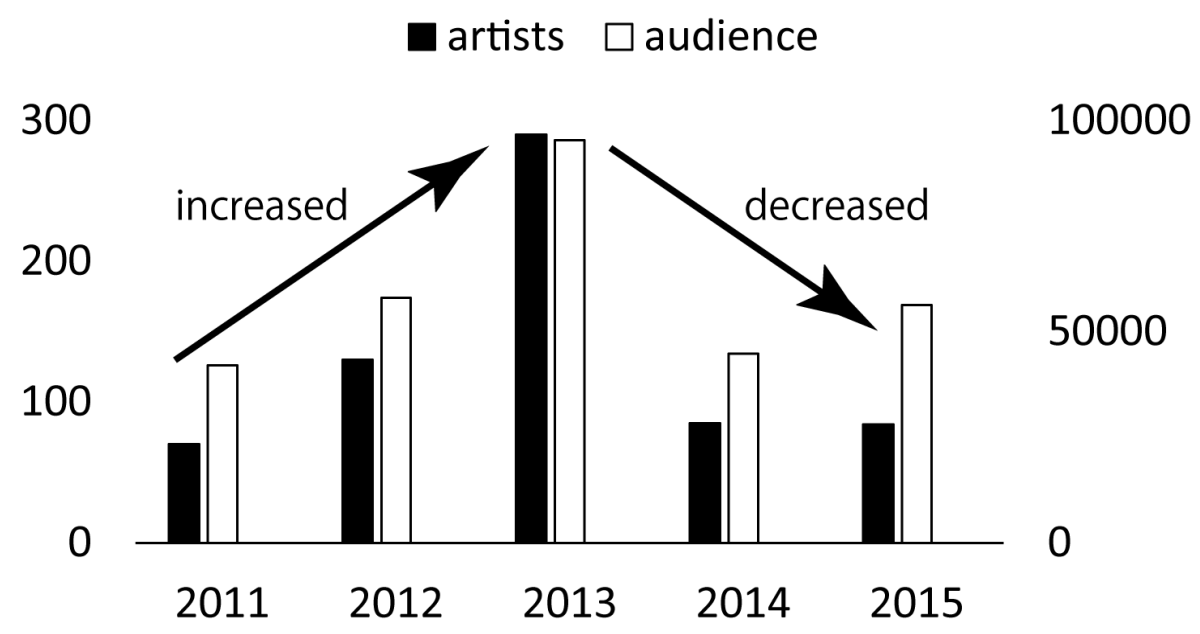

Figure 5: The number of artists (left axis) and audience attendance (right axis) in the Hanarart project for five years.

The author asked the curators who took part in Hanarart 2014 about how they communicated with residents. One curator welcomed the opportunity to work in Hanarart. She was satisfied with the level of communication with residents, saying:

I'm interested in how many individuals can be involved in contemporary art. Art projects can involve many individuals who usually do not have an interest in art. In order to show the value of art, particularly contemporary arts, curators are necessary as teachers. As a teacher, I was happy to be able to involve many residents who had not previously been interested in contemporary art. During the process, I was occasionally involved in with the residents' problems. It was necessary for our communication and the art project.

Another curator, on the other hand, was dissatisfied with the level of communication with the residents. 
In order to run art projects, residents should have a high level of literacy in contemporary art. In Nara, however, they did not. I could not show the works of a famous artist. There was opposition from the residents. I think we should not have attended the Hanarart.

Both of the curators had encountered problems with residents. Although their satisfaction was divided, the curators and residents had opportunities for genuine communication. The discussions did affect the content of the project in each area.

The author also interviewed the civil servant who first began Hanarart as a governmental project. She is now in another position. She told her objective opinion on Hanarart. She also told her expectation for Hanarart's future:

Hanarart should promote more and more communication between artists and residents. Fundamentally, artists and residents should have different interests. They cannot share all the same interests. Therefore, their communication would be able to create new findings for the interest and values of each. Through communication between different interests, they would be able to find new value in machiya buildings and contemporary art.

\section{DISCUSSION AND CONCLUSION}

Previous studies of art projects have not clarified the role of the coordinators who operate as a bridge between residents and artists. Without coordinators, it is difficult to devise loose connections between residents and artists in art projects. Outside artists have few opportunities to communicate with residents in many art projects. Some artists make use of art projects as a chance to exhibit. In such a case, the audience should be mainly composed of outsiders who are fans of the artists. Segregated from residents, outside artists and outsider audiences have little interest in community. Many artists who lack the opportunities to exhibit their work make use of art projects, even if they are paid little. The quantity of artists, including the many amateurs, who take part in art projects are evaluated, whereas the quality of their artwork is not judged. Grodach (2010) discusses the weakness of art projects, in the sense that talented artists may have little interest in attending art projects, fearing association with low-quality, amateur work. In such a case, art projects may become trivial events in which very few residents participate.

Few studies have examined the quality of art projects held in Japan. Based on the context of art projects expanding without critical checks on 
quality, Fujita (2016) criticises the situation of art projects with respect to how many artists fail to create original work. In fact, art projects have become abundant in Japan, because local municipalities do not need to contribute high levels of funding for them, as compared to other budgetary issues such as infrastructure and employment. While the number of art projects has increased, communication between residents and artists has often been overlooked. There have been few opportunities for site-specific contemporary art as well as for building cultural, creative areas with the help of art projects. However, when certain individuals take on the role of coordinator, they can help to bridge the loose connections between residents and artists and bring site-specific artwork to the fore.

In the case of the Hanarart project, the general director adopted the role of coordinator. He visited the area many times and to promote communication between resident groups and curators. As a resident of Osaka city, which is near Nara, he was close enough to the initial area to act as a bridge between residents and artists. He guided the art project not only as a means of community development but also as the exhibition of sincere art products through promoting communication between residents and artists. Not only the general director but also the curators acted as coordinators through their work involving artists and residents. Curators take on important roles. They exhibit art projects as places of discussion among various individuals, including artists and residents (Bishop 2012).

Small art projects should find their own ways to survive. Art projects are often regarded as a means of regional revitalisation, particularly in Japan, due to the impact of the success of the Naoshima project. This project is also well known for attracting excellent products, making use of the large capital available. Small art projects, such as Hanarart, cannot make use of large capital to invite the most famous artists or art products. Rather they try to give a chance for artists' or curators' growth by preparing communication between them and residents. For example, by distinguishing "Core" and "Plus" areas in an art project, artists and residents would be able to communicate and determine their different interests and values.

With regard to community development, Hanarart worked well. It promoted renovation and the repurposing of abandoned machiya buildings. Up until now, more than 30 abandoned buildings have been renovated, with plans for their ongoing use after acting as venues for Hanarart. One abandoned building is now used as a guesthouse. It randomly exhibits modern works of art. Previously abandoned buildings are now being used as stores for secondhand books, goods, and cuisine. Another building is now being used as 
the Hanarart office (Figure 6). Many of them are used for public purposes; so it is not only the operators who make use of them, but other residents and outsiders can also enjoy them. Even the residential buildings contribute to the area in the sense that individuals both live in and manage the buildings.

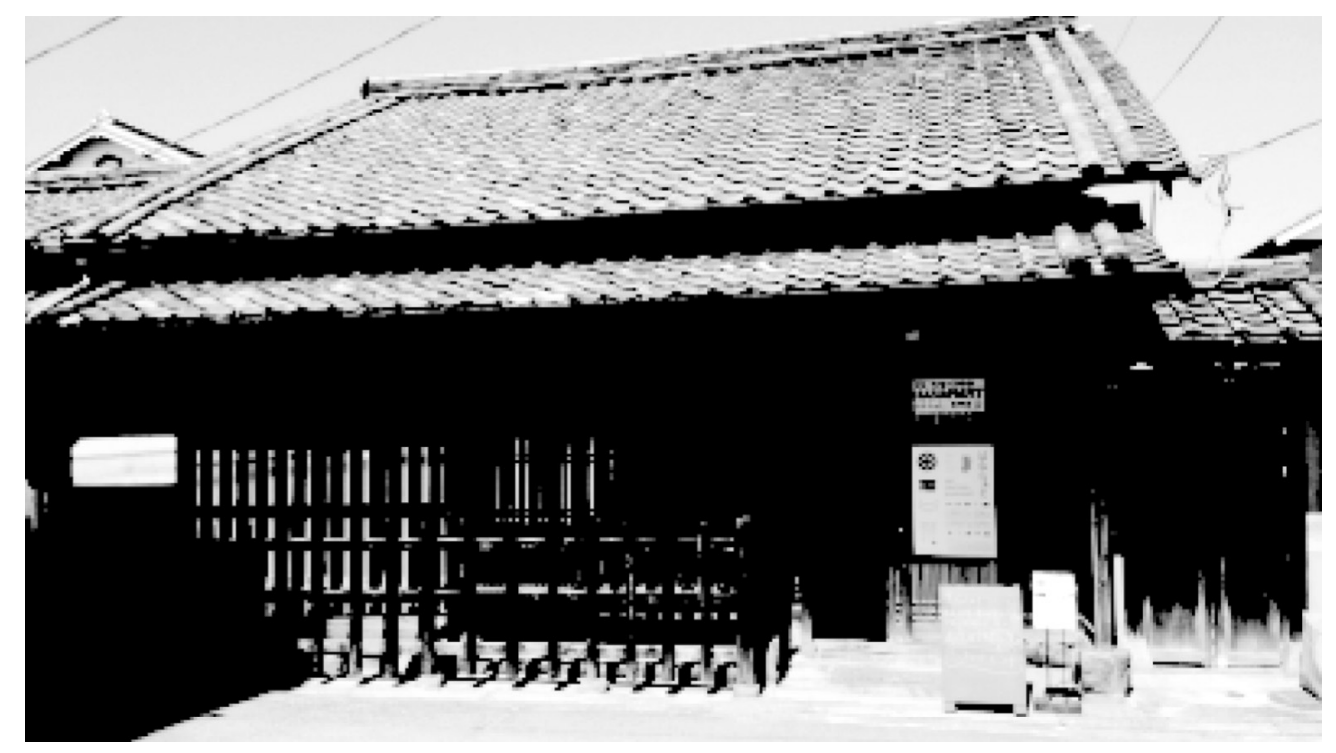

Figure 6: The Hanarart office renovated from a machiya building (from Hanarart homepage: http://blog.hanarart.jp/?eid=3).

Regarding the development of contemporary art, curators and artists gained benefit in relation to their careers by working with machiya buildings through the Hanarart project. They rarely had opportunities to work with machiya buildings; this was only possible in historical areas, such as Nara. Furthermore, communication with residents had a positive effect on the curators as well as the artists. One artist was awarded prizes soon after her exhibition at Hanarart. One curator now periodically sets up exhibitions in a renovated machiya building.

Accordingly, the Hanarart project worked not only at a community development level, but also by contributing to the promotion of contemporary art. Nowadays, the renovated machiya buildings welcome artists and their exhibitions. Not only residents, but also artists and other outsiders, can enjoy the machiya buildings. Resident groups have started to communicate across boundaries. The network has expanded, coming to include regional companies, universities, banks, municipalities, and so on. Different groups have had opportunities to communicate with each other thanks to the Hanarart project. During Hanarart, shops and cafes in the area attracted greater numbers of tourists. University students were able to work as cleaning crews in the area. In small art projects, several outcomes have been reported not in terms of 
economic gain but in social gain, such as improvements in social capital, inclusion of disabled individuals in community activities, the renovation of abandoned buildings, and disseminating the idea of contemporary art amongst residents (Yoshizawa 2011; Fuji 2012; Sawamura 2014). Small art projects may be the media by which residents renovate or revitalise their communities through activated communication with artists. As such, new connections appeared between various individuals, composed of both residents and outsiders. New connections are the result as well as the cause of developments in community and contemporary art.

In order to view loose connections, some symbols are required. The symbol of loose connections should be represented as a collaboration between machiya buildings and contemporary art. Coordinators and core members of the Hanarart project have grown by using these shared symbols. The shared symbols can involve many individuals at one time. Through the work of individuals, the machiya buildings have been retained and are activated with the help of contemporary art. Figure 7 is a schema of how the loose connections between residents and artists at Hanarart was made possible with the shared symbols.

Art, at its origins, works as a medium of communication between different individuals. Conkey (1980) discussed the possibility that rock art in prehistoric times worked as a medium of communication between different groups. Mauss (1925) noted that communication should involve heavy consumption, which should accompany the development of art. Such characteristics should also correspond to the Hanarart and try to involve many residents in communication with artists for community development. Some individuals, such as shamans, might take on the role of coordinators who bridge the gap between heterogeneous individuals.

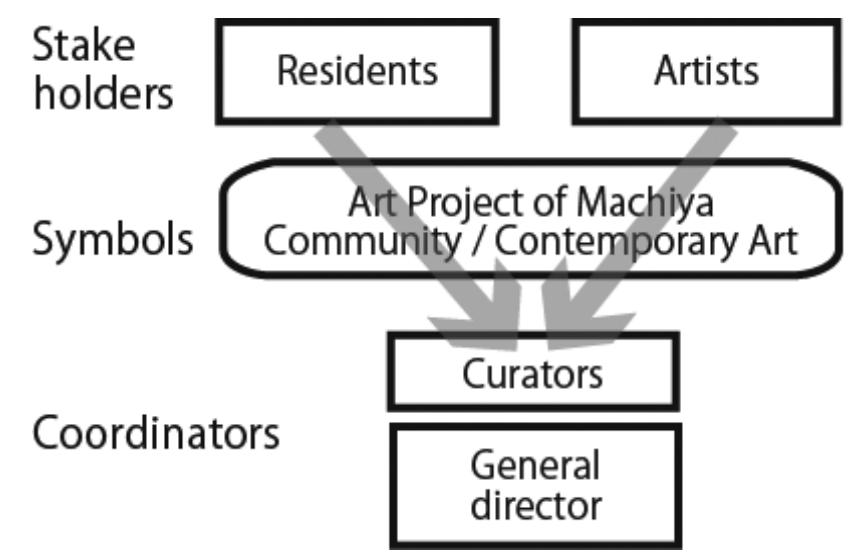

Figure 7: Loose connections at Hanarart. 
Burt and Nan answer the question, "Who gained the most from the loose connection between residents and outsiders?" They stated that the gains from bridging social capital are often concentrated on the coordinators within structural holes (Burt 1992; Nan 2001). The general director actually told me about his success after his attendance at Hanarart 2012. He has now been invited to participate in various projects as an independent curator. The general director said:

I want to provide opportunities to the curators for the advancement of their careers. Currently in Japan, independent curators cannot gain enough of a foothold. Through their curation in this project, attending curators like me have increased their chances.

He also told the author that Hanarart should be the yardstick for all art projects and that less efficient art projects should be stopped.

The place of loose connection should invite many individuals that are more heterogeneous. The place that includes different individuals and allows outsiders may be the cultural creative area. In the age of depopulation and aging in Japan, many regional areas now have to be independent from the national government concerning finance and governance. Since the fund from the Nara prefectural government is decreasing, the Hanarart office has to generate more funding itself. The Hanarart office is now collaborating with an increasing number of local companies in an attempt to generate funds. It also gathers revenue from audience entrance fees. It has begun crowd-funding campaigns to provide some services for outsider audiences.

The next step for Hanarart should be to examine how the art project could produce sincere artworks and continually promote communication between artists and residents. Communication between residents and outsiders actually gives growth to the value of the area. For instance, regional communities persist in "Treasure Hills" of Taipei and "Graham and Pearl Street" of Hong Kong, in spite of top-down pressure for reformation; residents and outsiders have collaboratively found the values of their areas, to which artists significantly contribute ( $\mathrm{Ng} 2014)$. Hanarart itself may be discontinued if it cannot demonstrate that successful relationships have been established between community development and contemporary art. Talented curators and artists are expected to grow and distinguish themselves from other abundant art projects. Should this continue to occur, then the regional communities of Nara might evolve into cultural, creative areas with the involvement of many talented individuals, unless it does not involve large capital. Then, 
community development may become possible, even if Nara is not profitable in terms of global capitalism. Communication across the boundary of regional communities is actually possible owing to globalisation. Talented individuals should select and visit places where they are likely to gain benefit in the age of globalisation (Horiuchi 2015).

\section{ACKNOWLEDGEMENTS}

This research was supported by the Ministry of Education, Culture, Sports, Science and Technology Japan (MEXT) grants 25101707, 16K07510, $16 \mathrm{~K} 07510$ and $16 \mathrm{H} 03698$. The author thanks the residents, artists and curators in the art project Hanarart. The author also thanks two anonymous reviewers for valuable comments and discussions. Finally, he would like to thank Enago (www.enago.jp) for the English language review.

\section{NOTES}

* Shiro Horiuchi was born in Kyoto, Japan, in 1975. He graduated from Kyoto University in 1998 and obtained $\mathrm{PhD}$ of Science in 2004 from the same university. He majors in regional and mathematical sociology. His main research interest is in the cooperation or coexistence of heterogeneous individuals. For the research in question, he analyses mathematical models, including computer simulations, based on game theory and population growth. He also engages in field work study of regional sociology, particularly interested in communication between urban and rural areas of Japan. He once worked as a coordinator that promotes cooperation among universities, municipalities, companies and non-profit organisations (NPOs) to build a creative area in Yamagata or Tohoku area of Japan. Shiro Horiuchi is now an associate professor of Hannan University, Japan. He teaches tourism sociology to the university students. Now he tries to build creative areas where residents and tourists cooperatively solve the problems and improve the value of the area. His selected publications are Shiro Horiuchi and Tatsuhiro Takahashi (2016), "Globalization and regional revitalization in a local university of Japan," in Globalization: Economic, Political and Social Issues (Ed. Bernadette Gonzalez), 149-159, Nova Publisher; Shiro Horiuchi (2015), "Emergence and collapse of the norm of resource sharing around locally abundant resources," Journal of Artificial Societies and Social Simulation 18 (4): 7; and Shiro Horiuchi and Mari Morino (2015), "How local cultures contribute to local communities? Case studies of Japanese spirits dance 'kagura'," International Journal of Social Science and Humanity 5: 58-62. He is a member of Japanese Association of Mathematical Sociology and Japan Institute of Tourism Research. 


\section{REFERENCES}

Bishop, C. 2012. Artificial hells: Participatory arts and the politics of spectatorship. London: Verso Books.

Bourriaud, N. 2002. Relational aesthetics. Dijon: Les presses du reel.

Burt, R. S. 1992. Structural holes: The social structure of competition. Cambridge: Harvard University Press.

Calhoun, C. J. 1980. Community: Toward a variable conceptualization for comparative research. Social History 5: 105-129, https://doi.org/10.1080/03071028008567472.

Cohen,A. P. 1985. The symbolic construction of community. London: Tavistock Publications, https://doi.org/10.4324/9780203323373.

Coleman, J. S. 1988. Social capital in the creation of human capital. American Journal of Sociology 94: S95-S120, https://doi.org/10.1086/228943.

Conkey, M. W. 1980. The identification of prehistoric hunter-gatherer aggregation sites: The case of Altamira. Current Anthropology 21: 609-630, https://doi. org/10.1086/202540.

Delanty, G. 2003. Community. London: Routledge.

Dore, R. P. 1994. Shinohata: A portrait of a Japanese village. California: University of California Press.

Florida, R. 2002. The rise of the creative class: And how it's transforming work, leisure, community and everyday life. New York: Basic Books.

Fuji, H. 2012. Chiiki wo kaeru soft power [Soft power reforming region]. Tokyo: Seigensha.

Fujita, N. 2016. Chiiki art: Bigaku, seido, nihon [Community-engaged art project].Tokyo: Horinouchi Shuppan.

Granovetter, M. S. 1973. The strength of weak tie. American Journal of Sociology 78: 1360-1380, https://doi.org/10.1086/225469.

Grodach, C. 2010. Art spaces, public space, and the link to community development. Community Development Journal 45: 474-493, https://doi.org/10.1093/cdj/bsp018.

Hechter, M. 1987. Principles of group solidarity. Berkeley: University of California Press.

Helguera, P. 2011. Education for socially engaged art: A materials and techniques handbook. Maryland: Jorge Pinto Books.

Horiuchi, S. 2008. Affiliative segregation of outsiders from a community: Bonding and bridging social capital in Hachimori, Japan. International Journal of Japanese Sociology 17: 91-100, https://doi.org/10.1111/j.1475-6781.2008.00111.x. . 2015. Globalisation may cause cultural accumulation in the whole population. In Agent-based approaches in economic and social complex systems VIII, ed. Nakai, Y., Koyama, Y. and Terano, T., 27-37. Tokyo: Springer Japan, https://doi. org/10.1007/978-4-431-55236-9_3.

Horiuchi, S., Kanazawa, Y., Suzuki, T. and Takikawa, H. 2013. Who gain resources from which social capital? A mathematical review. In Social capital: Theory, measurement and outcome, ed. Johnson, C. D., 3-28. New York: Nova Publisher.

Horiuchi, S. and Takahashi, T. (2016). Globalisation and regional revitalization in a local university of Japan. In Globalisation: Economic, political and social issues, ed. Gonzalez, B., 149-159. New York: Nova Publisher.

Jacobs, J. 1984. Cities and the wealth of nations: Principles of economic life. New York: Random House. 
Kumakura, J. 2014. Art project: Geijutsu to kyoso suru shakai [Art project: Society with art]. Tokyo: Suiyosha.

Kwon, M. 2004. One place after another: Site-specific art and locational identity. Cambridge, MA: MIT Press.

Landry, C. 2000. The creative city: A toolkit for urban innovators. New York: Routledge.

Lin, N. 2001. Social capital: A theory of social structure and action. New York: Cambridge University Press, https://doi.org/10.1017/CBO9780511815447.

MacIver, R. M. 1924. Community: A sociological study. London: Macmillan.

Masuda, H. 2014. Chifo shometsu [Regional areas disappearing]. Tokyo: Chuo Koron Sha.

Mauss, M. 1925. The gift: Forms and functions of exchange in archaic society. New York: Free Press.

Nan, L. 2001. Social capital: A theory of social structure and action. Cambridge: Cambridge University Press.

Newman, T., Curtis, K. and Stephens, J. 2003. Do community-based arts projects result in social gains? A review of the literature. Community Development Journal 38: 310-322, https://doi.org/10.1093/cdj/38.4.310.

$\mathrm{Ng}, \mathrm{M} .2014$. Intellectuals and the production of space in the urban renewal process in Hong Kong and Taipei. Planning Theory \& Practice 15: 77-92, https://doi.org/10. 1080/14649357.2013.870224.

Okuda, M. 1983. Toshi community no riron [Theory of city community]. Tokyo: University of Tokyo Press.

Olson, M. 1965. The logic of collective action: Public goods and the theory of groups. Cambridge: Harvard University Press.

Orikuchi, S. 2003. Kodai kenkyu III. Tokyo: Tyuo-Koron.

Ostrom, E. 1990. Governing the commons: The evolution of institutions for collective action. Cambridge: Cambridge University Press, https://doi.org/10.1017/ CBO9780511807763.

Portes, A. 1998. Social capital: Its origin and applications in modern sociology. Annual Review of Sociology 24: 1-24, https://doi.org/10.1146/annurev.soc.24.1.1.

Putnam, R. D. 2000. Bowling alone: The collapse and revival of American community. New York: Simon \& Schuster, https://doi.org/10.1145/358916.361990.

Sasaki, M. 2012. Sozo toshi eno chosen [Challenges for creative cities]. Tokyo: Iwanamishoten.

Sasaki, M., Kawaida, S. and Hagiwara, M. 2014. Sozo noson [Creative villages]. Tokyo: Gakugeishuppansha.

Sassen, S. 2001. The global city: NewYork, London, Tokyo. Princeton, N.J.: Princeton University Press, https://doi.org/10.1515/9781400847488.

Sawamura, A. 2014. Art wa Chiiki wo Kaetaka: Echigo-Tsumari Daichinogeijutusai no Juusann-nen: 2000-2012 [Did art reform the region? Echigo-Tsumari Triennale's thirteen years: 2000-2012]. Tokyo: Keiogijuku University Press.

Stuiver, M., van der Jagt, P., van Erven, E. and Hoving, I. 2013. The potentials of art to involve citizens in regional transitions: Exploring a site-specific performance in Haarzuilens, the Netherlands. Community Development Journal 48: 298-312, https://doi.org/10.1093/cdj/bss022.

Suzuki, E. 1968. Nihon noson shakaigaku genri [Japan rural area: Sociological principle]. Tokyo: Mi-raisha. 
Woolcock, M. 1998. Social capital and economic development: Toward a theoretical synthesis and policy framework. Theory and Society 27: 151-208, https://doi. org/10.1023/A:1006884930135.

Wuthnow, R. 1998. Loose connections: Joining together in America's fragmented communities. Cambridge: Harvard University Press.

Yoshizawa, Y. 2011. Geijutsu wa Shakai wo Kaeruka: Bunkaseisan no Shakaigaku karano Sekkin [Can art reform the society? approaches from sociology of culture production]. Tokyo: Seikyusha. 